\title{
Complex networks identify spatial patterns of extreme rainfall events of the South American Monsoon System
}

\author{
Niklas Boers, ${ }^{1,2}$ Bodo Bookhagen, ${ }^{3}$ Norbert Marwan, ${ }^{2}$ Jürgen Kurths,,${ }^{1,2}$ and \\ José Marengo 4 \\ Received 21 April 2013; revised 16 June 2013; accepted 19 June 2013.
}

[1] We investigate the spatial characteristics of extreme rainfall synchronicity of the South American Monsoon System (SAMS) by means of Complex Networks (CN). By introducing a new combination of $\mathrm{CN}$ measures and interpreting it in a climatic context, we investigate climatic linkages and classify the spatial characteristics of extreme rainfall synchronicity. Although our approach is based on only one variable (rainfall), it reveals the most important features of the SAMS, such as the main moisture pathways, areas with frequent development of Mesoscale Convective Systems (MCS), and the major convergence zones. In addition, our results reveal substantial differences between the spatial structures of rainfall synchronicity above the 90th and above the 95th percentiles. Most notably, events above the 95th percentile contribute stronger to MCS in the La Plata Basin. Citation: Boers, N., B. Bookhagen, N. Marwan, J. Kurths, and J. Marengo (2013), Complex networks identify spatial patterns of extreme rainfall events of the South American Monsoon System, Geophys. Res. Lett., 40, doi:10.1002/grl.50681.

\section{Introduction}

[2] Recently, Complex Networks (CN) have been successfully applied in the analysis of climate time series [Tsonis et al., 2007; Yamasaki et al., 2008; Donges et al., 2009a; Malik et al., 2011; Steinhaeuser et al., 2012; Berezin et al., 2012]. In most cases, they are used to represent the strongest correlations among time series at different locations. Among other applications, this can lead to the detection of climatic teleconnections [Donges et al., 2009b, 2011] as well as to the identification of distinct climate regimes [Yamasaki et al., 2009; Gozolchiani et al., 2011].

[3] Here we use $\mathrm{CN}$ to analyze the South American Monsoon System (SAMS), which is particularly well studied and thus suitable for demonstrating how $\mathrm{CN}$ reproduce known climatic features, but also how they reveal previously undocumented results. Specifically, we find important spatial differences in the synchronicity structure of events above

Additional supporting information may be found in the online version of this article.

${ }^{1}$ Department of Physics, Humboldt University, Berlin, Germany.

${ }^{2}$ Potsdam Institute for Climate Impact Research, Potsdam, Brandenburg, Germany.

${ }^{3}$ Department of Geography, University of California, Santa Barbara, California, USA

${ }^{4}$ CCST INPE, Cachoeira Paulista, São Paulo, Brazil.

Corresponding author: N. Boers, Potsdam Institute for Climate Impact Research, PO Box 601203, 14412 Potsdam, Germany. (boers@pikpotsdam.de)

(C)2013. American Geophysical Union. All Rights Reserved. 0094-8276/13/10.1002/grl.50681 the 90th and the 95th percentile. We emphasize that the $\mathrm{CN}$ approach to climate time series analysis does not substitute but complement more traditional techniques. The simplicity of the approach together with the consistency of the results with previous studies of the SAMS shows the unique potential of $\mathrm{CN}$ approaches for climatological studies.

[4] We employ a measure that quantifies the degree of synchronization between extreme events of two given time series. A similar approach was recently chosen by Malik et al. [2011], who have analyzed extreme rainfall events in the Indian Monsoon System. The spatial characteristics of CNs calculated from the most synchronous events within a given time period are analyzed using several $\mathrm{CN}$ measures, for which we provide climatological interpretations. Most previous $\mathrm{CN}$ approaches focused on large-scale analyses of low-to-moderate spatiotemporal resolution data [Tsonis et al., 2007; Gozolchiani et al., 2008; Yamasaki et al., 2008; Donges et al., 2009a]. But high spatiotemporal resolution data derived from station networks or satellite data (such as the here used TRMM 3B42 daily satellite product) are crucial for identifying low-frequency and high-magnitude hydrometeoric events. By analyzing these data with $\mathrm{CN}$, we unravel spatial and temporal connections between atmospheric processes that directly link to natural hazards occurring at the Earth's surface. We emphasize that the small-scale linkages, orographic rainfall barriers, and important climate patterns and meteorological mechanisms are only adequately resolved with data on high spatial and temporal scales.

\section{Climatic Setting, Data, and Methods}

\subsection{South American Monsoon System (SAMS)}

[5] Here we provide a brief overview of the most important climatic features of the SAMS. For an in-depth review, we refer to, e.g., Vera et al. [2006] and Marengo et al. [2012].

[6] Trade winds in the vicinity of the Intertropical Convergence Zone (ITCZ) together with differential heating between ocean and land in the monsoon season (DecemberJanuary-February (DJF)) are responsible for large amounts of low-level moisture transport from the tropical Atlantic Ocean onto the continent [Zhou et al., 1998]. The South Atlantic Convergence Zone (SACZ), a convective band of precipitation extending southeastward from the central Amazon Basin at approximately $10^{\circ} \mathrm{S}$ (Figure $1 \mathrm{~b}$ ), has been described as one of the most distinctive features of the SAMS [Nogués-Paegle et al., 2002; Carvalho et al., 2002, 2004]. Its variability is characterized by a dipole-like pattern [Nogués-Paegle et al., 1997; Grimm and Zilli, 2009], 


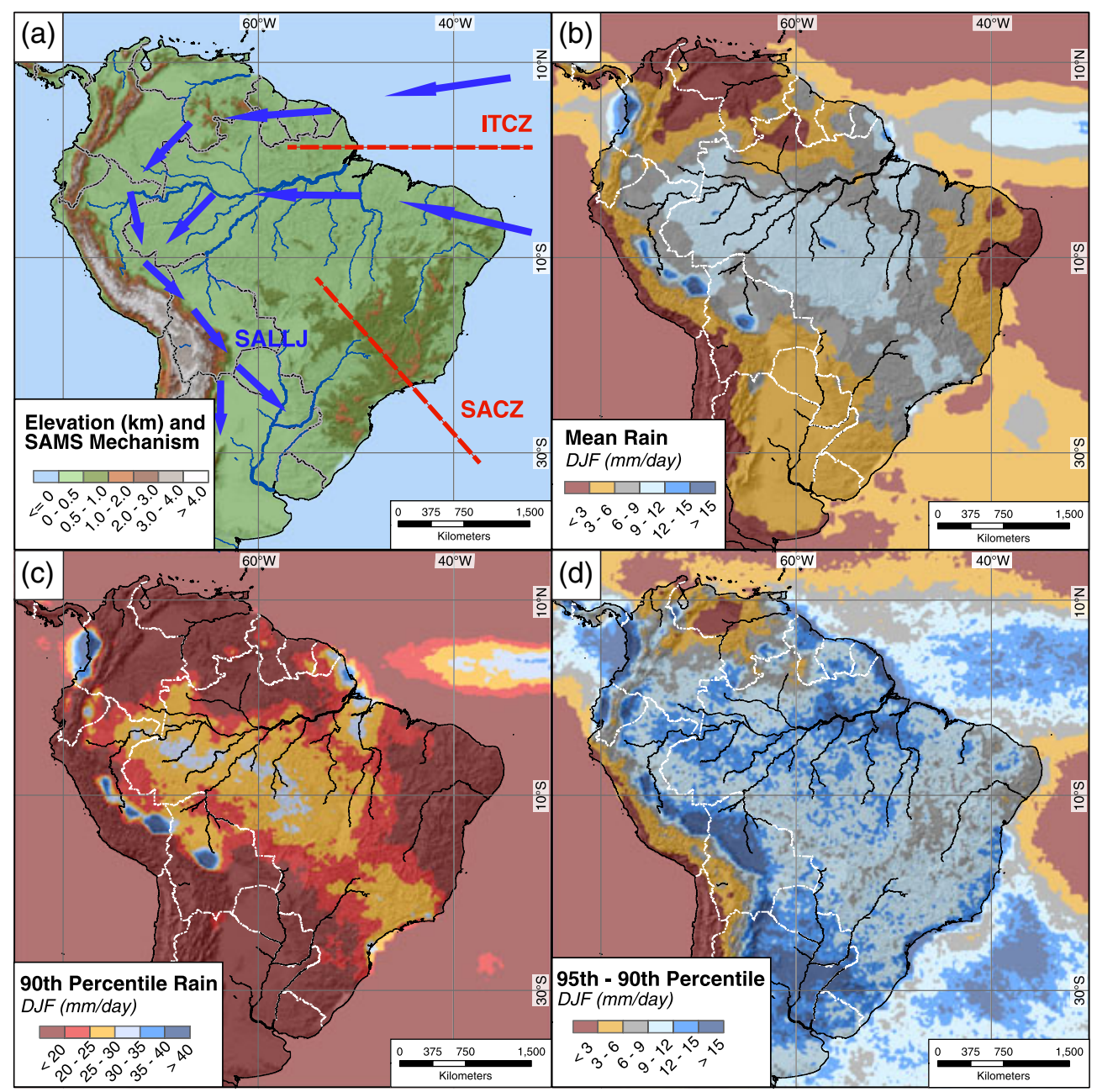

Figure 1. (a) Elevation and key features of the SAMS. (b) Mean daily rainfall for the core monsoon season from December to February (DJF). (c) The 90th percentile of rainfall for DJF. (d) Difference of the 95th and the 90th percentile for DJF.

with enhanced precipitation in the SACZ when precipitation in SE South America is suppressed and vice versa. The low-level flow from the tropical Atlantic ocean toward the Amazon is ultimately blocked by the Andes mountains and channeled southward, establishing the South American Low-Level Jet (SALLJ) [Marengo et al., 2004]. The SALLJ has been identified to be an important moisture source for the development of Mesoscale Convective Systems (MCS) in the La Plata Basin [Nicolini et al., 2002; Salio et al., 2007].

\subsection{Data}

[7] We employ the TRMM 3B42 V7 daily satellite product from 1 January 1998 to 31 December 2012 (15 years) with spatial coverage of $40^{\circ} \mathrm{S}$ to $15^{\circ} \mathrm{N}$ and $85^{\circ} \mathrm{W}$ to $30^{\circ} \mathrm{W}$ at a resolution of $0.25^{\circ} \times 0.25^{\circ}$ with rainfall values in $\mathrm{mm} / \mathrm{d}$ (Figure 1) [Huffman et al., 2007].

\subsection{Methods}

[8] Here we provide a brief synopsis of our $\mathrm{CN}$ approach. We refer to the supporting information and [Malik et al., 2011] for additional information.

[9] At each grid point and for each 3 months season (December-January-February (DJF), March-April-May (MAM), June-July-August (JJA), September-OctoberNovember (SON)), we consider events above the 90th and 95th percentile of the rainfall time series (15 years of data $\times 90$ days per season $\times 10 \%(5 \%)=135(68)$ events at each grid point). Grid points with less than 135 (68) wet days are discarded from the analysis (Figure 1c). These are regions in the eastern Pacific and near the Atacama Desert in northern Chile with very low rainfall amounts and only very infrequent rainfall events.

[10] Next, we apply the method of Event Synchronization (ES) to the event time series [Quiroga et al., 2002; Malik et al., 2011]. For two grid points $i$ and $j$, ES separately measures the synchronicity of events at $j$ following events at $i$ and vice versa. ES incorporates a dynamical delay as opposed to the static delay used when, e.g., calculating Pearson correlation at some time lag. In other words, ES does not assume any temporal coherence between time series, as it is generally assumed by most other correlation techniques.

[11] We compute ES using a maximal time delay of $\tau_{\max }=$ 3 days. For each grid point pair $i, j$, we summed the values for both directions (from $i$ to $j$ and from $j$ to $i$ ), thereby loosing all information about directions. Upon calculating ES for all pairs of grid points, we consider events at a grid point $j$ to be synchronous to events at a grid point $i$ if the corresponding value of ES is among the highest $2 \%$ of all values. We denote this by a link between $i$ and $j$ and will say that 


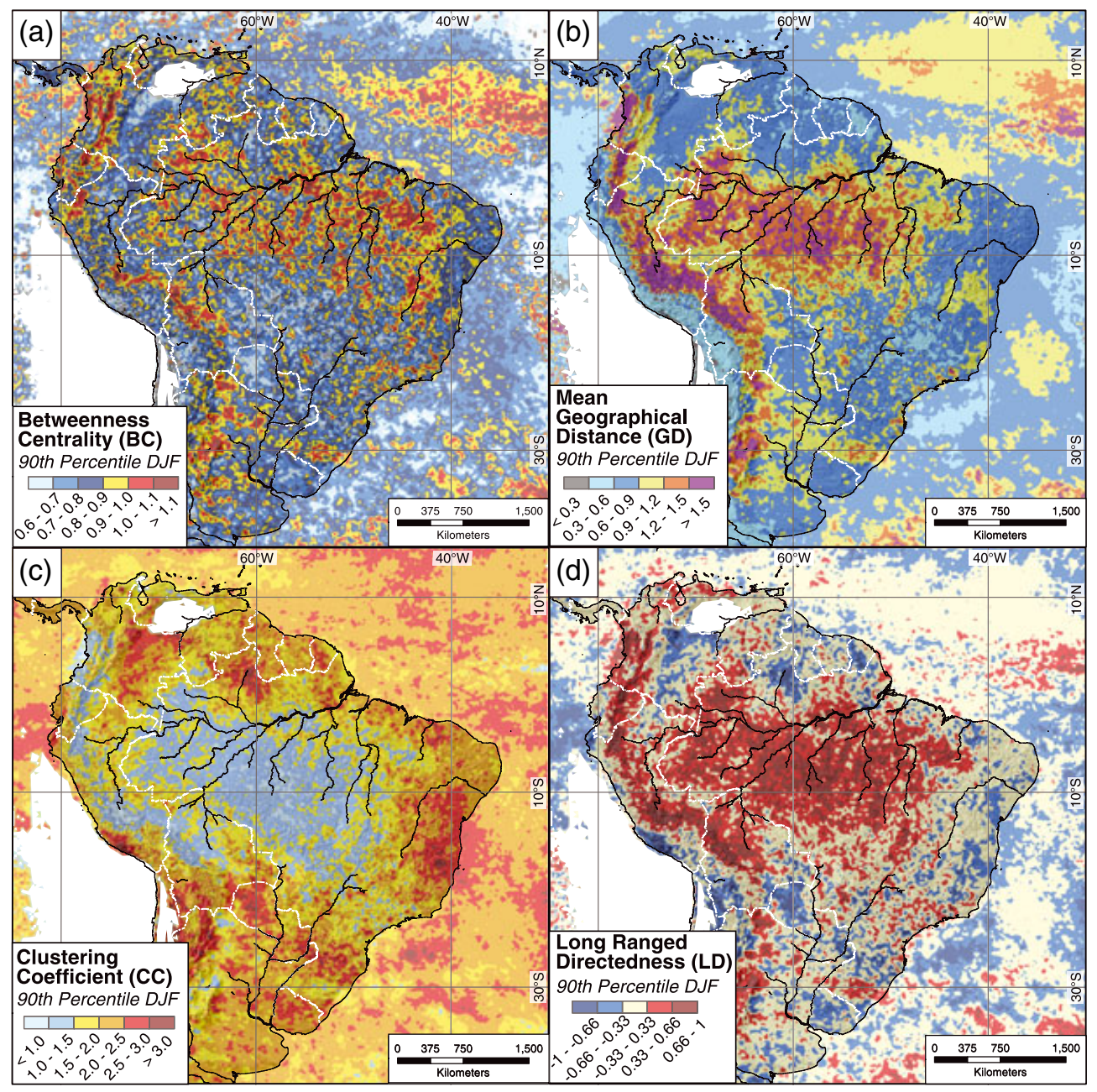

Figure 2. (a) Betweenness centrality (BC) on a logarithmic scale for DJF. This measure indicates the importance of a grid point for the long-range spatial propagation of extreme rainfall events. We observe high values in several areas that are crucial for water-vapor transport, especially in the central Amazon Basin and along the orographic barrier of the eastern Andes. (b) Mean geographical distance (GD) for the same time period. For example, high values are found in the central Amazon Basin and along the eastern Andean slopes, which can be explained by their important role for moisture transport to the subtropics and the large spatial scales involved. (c) The clustering coefficient (CC) for the same time period. It measures the degree of spatial coherence in the distribution of extreme rainfall. Note the high values in southeastern South America, where Mesoscale Convective Systems (MCS) frequently develop. (d) Long-ranged directedness (LD) for the same time period. Low values indicate areas where extreme rainfall occurs regionally coherently as, e.g., in MCS, while high values indicate areas where extreme rainfall propagates on narrow transport routes over large spatial distances, as, e.g., along the eastern Andes slopes.

$i$ and $j$ are connected. In this way, we obtain an undirected $\mathrm{CN}$ for each 3 months season. For DJF, the lowest value of ES, which is represented by a link is $0.34(0.23)$ for events above the 90th (95th) percentile. In the supporting information, we show that a test of statistical significance based on an independent and uniformly random distribution of events yields a $P$ value of $0.03(0.01)$ for this threshold.

[12] We derive spatial patterns from these networks with the following four $\mathrm{CN}$ measures: betweenness centrality (BC), mean geographical distance (GD), the clustering coefficient (CC), and long-ranged directedness (LD).

[13] First, we employ betweenness centrality (BC). It is based on the concept of shortest geodesic paths in the $\mathrm{CN}$, which are the shortest sequences of links leading from one grid point to another. For given grid points $j$ and $k$, we first look for all shortest paths between $j$ and $k$ and then calculate the ratio of the number of such shortest $\mathrm{CN}$ paths, which pass through a third grid point $i$, and the total number of shortest $\mathrm{CN}$ paths between $j$ and $k$. BC at grid point $i$ is then defined as the sum of these ratios over all $j$ and $k$. If a grid point lies on many such shortest paths between any pairs of grid points, its $\mathrm{BC}$ will be high, and we interpret it to be important for the propagation of extreme rainfall events, in particular over large spatial distances.

[14] Second, we calculate the mean geographical distance (GD) of the connections at a grid point. We use this measure to estimate the spatial scales at which a grid point is connected to other regions. Areas with high GD are thus likely to be part of teleconnection patterns.

[15] Third, we calculate the clustering coefficient (CC), which at a given grid point is defined as the relative frequency of pairs of $\mathrm{CN}$ neighbors of this grid point that 


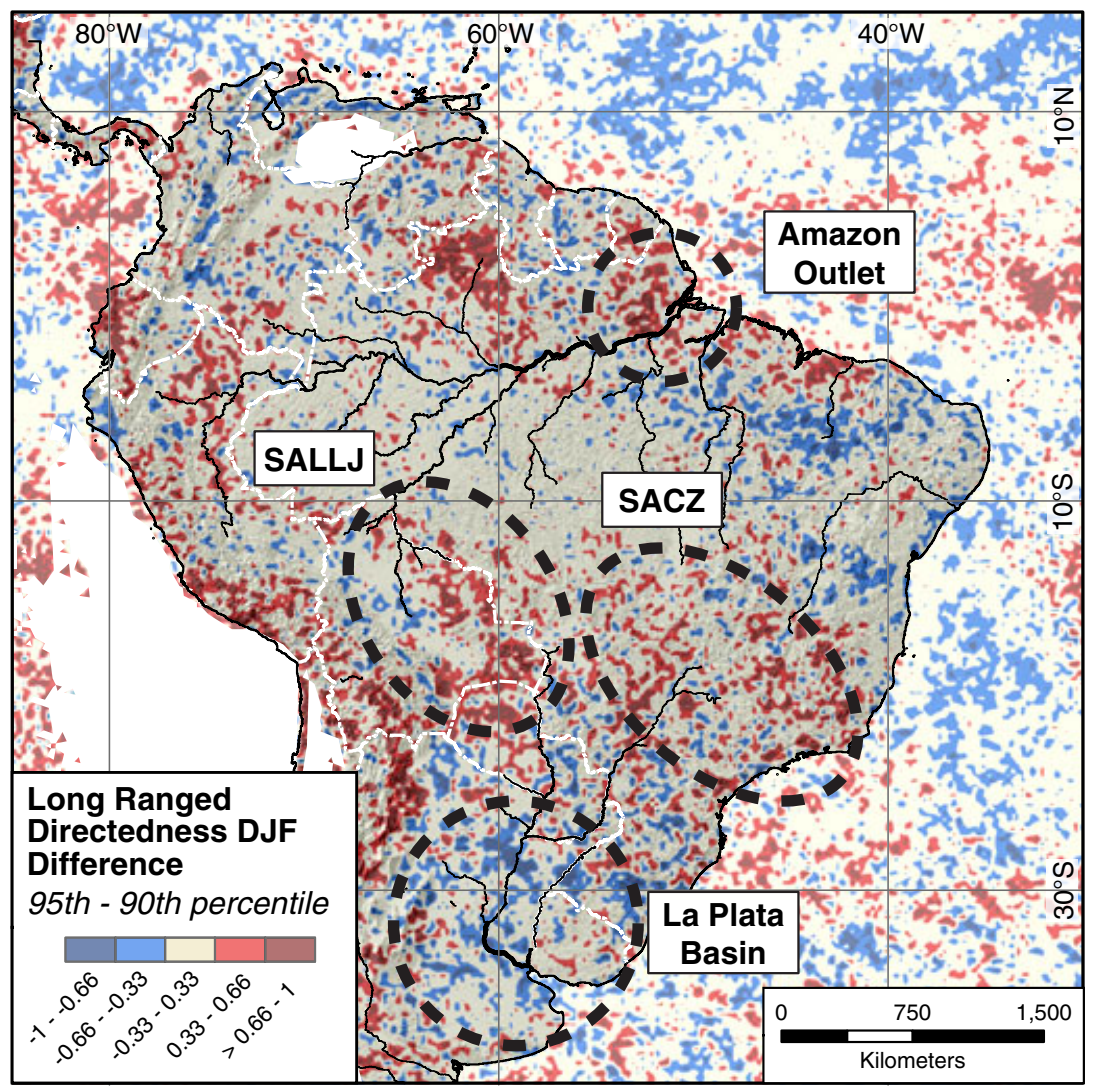

Figure 3. Difference of LD of the 95th and the 90th percentile for DJF. High values indicate areas which are more important for the large-scale propagation of events above the 95th percentile, while low values indicate areas where regional clustering of events (as, e.g., in MCS) enhances for events above the 95th percentile.

are $\mathrm{CN}$ neighbors themselves. A region with high $\mathrm{CC}$ is interpreted to exhibit rather large spatial coherence.

[16] Fourth, we introduce a combination of these three measures called long-ranged directedness (LD). The three measures $\mathrm{BC}, \mathrm{GD}$, and CC illustrate complementary aspects of the $\mathrm{CN}$, and our analysis of the SAMS is based on their combination. This allows us to obtain much more detailed and robust insights into the underlying mechanisms of the SAMS than with just one $\mathrm{CN}$ measure alone. We classify a region's extreme rainfall characteristics from regionally clustered to long-ranged and directed by introducing LD: upon calculating the normalized ranks of $\mathrm{BC}$ (NRBC), GD (NRGD), and CC (NRCC), we put LD $=1 / 2 \mathrm{NRBC}+$ 1/2NRGD - NRCC (Figure 2d). For example, we expect extreme rainfall in a region with low $\mathrm{LD}$ (resulting from low $\mathrm{BC}$ and low GD in combination with high $\mathrm{CC}$ ) to occur spatially coherently (and extensively within that region) with little long-range impacts. In particular, frequent spatially extensive contiguous events will lead to this combination of $\mathrm{CN}$ measures, which can thus be an indicator for regions with more frequent development of MCS. On the other hand, extreme rainfall in a region with high $\mathrm{LD}$ values resulting from high $\mathrm{BC}$ and high GD in combination with low CC is expected to involve highly dynamical, directed moisture transport processes along narrow transport routes and over large spatial scales.

[17] In the supporting information, we provide a figure of a small example network in order to explain these measures also graphically.
[18] The fact that we only consider a bounded spatial domain can influence the spatial distribution of these four $\mathrm{CN}$ measures, as it may impose restrictions on the placement of possible CN links. This is commonly referred to as the effect of spatial embedding of the $\mathrm{CN}$. We correct for this effect following Rheinwalt et al. [2012] by dividing the value of each measure at each grid point $\left(M_{i}\right)$ by the value expected from the spatial embedding alone. This expectation value $<M_{i}>$ is obtained by averaging $M_{i}$ over a collection of random surrogate networks preserving only the relative frequency of links given their geographical distance (we give a more detailed explanation in the supporting information).

\section{Results}

\subsection{Extreme Rainfall ( $>$ 90th Percentile)}

[19] Here we present our results for the 90th percentile of the peak monsoon season (DJF). Figures for the remaining seasons and for events above the 95th percentile can be found in the supporting information.

[20] We observe a region of high BC and GD but rather low $\mathrm{CC}$ and therefore high $\mathrm{LD}$ over the tropical Atlantic Ocean between the equator and $5^{\circ} \mathrm{N}$ (Figure 2). This corresponds to the climatological position of the ITCZ. The same combination of $\mathrm{BC}, \mathrm{CC}$, and $\mathrm{GD}$, resulting in even higher $\mathrm{LD}$, can be observed over a large continuous area in the central Amazon Basin around $5^{\circ} \mathrm{S}, 60^{\circ} \mathrm{W}$ (Figure 2).

[21] Moderately high LD values extend from the central Amazon southeastward toward southeast Brazil (Figure 2d). 
This wide branch, meeting the coast at about $20^{\circ} \mathrm{S}$, corresponds to the climatological position of the continental part of the SACZ [Carvalho et al., 2004].

[22] Starting at about $10^{\circ} \mathrm{S}, 70^{\circ} \mathrm{W}$, a concise narrow band of high LD extends southeastward along the eastern slope of the Andes. In northern Argentina, this band splits into two branches, one leading southward until approximately $30^{\circ} \mathrm{S}$ (Figure 2) and one leading eastward, reaching the Atlantic coast in southernmost Brazil. The position of the northern part of this signature, before it splits into two branches, coincides with that of strong orographic rainfall at the eastern Andean slopes associated with low-level winds transporting moisture from the Amazon Basin toward the subtropics (Figure 1) [Bookhagen and Strecker, 2008].

[23] Large parts of the La Plata Basin in Paraguay, southern Brazil, NE Argentina, and Uruguay are characterized by high $\mathrm{CC}$, rather low BC and GD and thus low LD (Figure 2). These areas are known for their frequent development of MCS [Salio et al., 2007]. This region is intermitted by the eastern branch of high LD mentioned in the previous paragraph.

\subsection{Most Extreme Rainfall ( $>$ 95th Percentile)}

[24] When only events above the 95th percentile are taken into account, LD is decreased as compared to the 90th percentile in the La Plata Basin. In contrast, LD exhibits increased values in the SACZ, in western Paraguay, and at the outlet of the Amazon River (Figure 3).

\section{Discussion}

\subsection{Rainfall $>$ 90th Percentile}

[25] The region adjacent to the ITCZ is identified as the most important source for the large-scale distribution of extreme rainfall over the entire continent, as it is the only oceanic region in the considered domain with high $\mathrm{BC}$.

[26] The importance of the central Amazon Basin for the spatial distribution of extreme rainfall to most of the remaining continent can be explained by its geographical position combined with its dense vegetation cover: Rapid propagation of squall lines from the northeastern coast of Brazil into the Amazon Basin are responsible for most of the spatial distribution of extreme rainfall in this region [Garreaud and Wallace, 1997]. The landfall of these thunderstorm systems leads to locally high clustering near the outlet of the Amazon River (Figure 2c). These storm lines are followed by enhanced moisture inflow and convective activity because of latent heat release and the resulting strengthening of low-level easterlies [Cohen et al., 1995]. Evapotranspiration recharges the moisture content of the low-level atmosphere [Eltahir and Bras, 2006; Lettau et al., 1979] and the deep convection leads to further extreme rainfall. At the same time, the enhanced low-level winds transport the moisture further west and south, which leads to synchronized rainfall there and thus explains the high $\mathrm{BC}$ values in the central Amazon Basin (Figure 2a).

[27] The SACZ is shaped by the continental wind patterns mainly resulting from the interplay of trade winds and the orographic barrier of the Andes [Carvalho et al., 2004]. This suggests that extreme rainfall in this area is dictated by long-ranged, directed transport processes, which is consistent with high LD (Figure 2d).
[28] The band of high LD along the eastern slopes of the Bolivian Andes (Figure 2d) highlights the importance of this region for the large-scale moisture transport (we emphasize the particularly high GD in this region, Figure 2b). Its geographical position suggests that this $\mathrm{CN}$ signature is due to the interplay of orographic effects and the conveyer belt providing moisture for subtropical South America [Bookhagen and Strecker, 2008; Arraut et al., 2012]. It is located slightly farther west than the climatological position of SALLJ [Marengo et al., 2004], presumably because orographic effects overprint the moisture advection signal related to these wind systems. In other words, since our approach is only based on rainfall events, the resulting $\mathrm{CN}$ measures reveal locations that are crucial for the synchronicity of extreme rainfall associated with large-scale moisture transport, but not the transport processes themselves. These rainfall events are strongly enhanced by orographic effects, which shift the patterns toward the Andes, i.e., westward from the climatological position of the main wind routes. We stress that only high spatiotemporal resolution data are able to uncover the spatial distinction of these features.

[29] The position of the branch of high LD extending southward from the border of Bolivia and Argentina suggests that this pattern corresponds to extreme rainfall associated with moisture transport by the Chaco Jet, a southward extension of the SALLJ controlled by the Chaco Low [Salio et al., 2002; Saulo et al., 2004]. We interpret the branch of high LD extending eastward from the border of Bolivia and Argentina to be the transport route toward the La Plata Basin. This area is characterized by high synchronicity of extreme events, and it is consistent in shape with the climatological moisture transport route [Arraut et al., 2012].

[30] Furthermore, our $\mathrm{CN}$ measures identify regions with frequent occurrences of MCS in southeastern South America, characterized by low LD. In particular, we emphasize the high CC in Paraguay, the typical exit region of the SALLJ, which provides moisture for MCS. We note that areas corresponding to the eastern branch of high (instead of low) LD have been previously described to exhibit frequent MCS development as well [Durkee et al., 2009; Durkee and Mote, 2010]. This discrepancy stems from an additional climatological process, namely the directed propagation of extreme events along the rather narrow eastern branch of high $\mathrm{BC}$, which seems to overprint the expected signature of high $\mathrm{CC}$.

\subsection{Comparison of Spatial Patterns for Rainfall Above the 90th and Above the 95th Percentiles}

[31] The substantial differences in LD between extreme ( $>$ 90th percentile) and most extreme ( $>$ 95th percentile) rainfall suggest different spatial patterns for the propagation of events (Figure 3). For the most extreme events, the role of the SACZ is enhanced (Figure 3). We attribute this to higher synchronicity of events above the 95th percentile along the SACZ due to an increased number of events during phases of intensified SACZ, as was previously described by Carvalho et al. [2004]. Decreased LD values for events above the 95th percentile in the La Plata Basin indicate an enhanced role of MCS for the most extreme rainfall events in this region because, as described above, low LD is interpreted to indicate regions with frequent MCS development. On the other hand, increased values of LD in western Paraguay 
suggest that the SALLJ is more important for the directed propagation of events above the 95th percentile in this region. Similarly, we infer that the squall lines in NE Brazil are more important for the large-scale propagation of the most extreme events.

\section{Conclusion}

[32] We analyzed the synchronicity of extreme rainfall of the South American Monsoon System (SAMS) by means of Complex Networks $(\mathrm{CN})$. The $\mathrm{CN}$ were constructed from Event Synchronization of seasonal extreme events, which were obtained from high spatiotemporal resolution data (daily data at $0.25^{\circ} \times 0.25^{\circ}$ ) derived from remote-sensing measurements. We introduced a new combination of $\mathrm{CN}$ measures called long-ranged directedness, which quantifies the characteristics of spatial distribution and geographic connectivity of extreme rainfall. The spatial patterns exhibited by this new measure reveal the most important large-scale features of the SAMS when considering events above the 90th percentile. These include the propagation of mesoscale storm systems, areas of deep convection in the Amazon Basin, the main rainfall-transport routes to the subtropics including the South American Low-Level Jet and its interplay with orographic processes at the eastern Andean slopes, as well as the Intertropical Convergence Zone and the South Atlantic Convergence Zone (SACZ). In a final step, we have analyzed the differences in spatial patterns between $\mathrm{CN}$ measures above the 90th and 95th percentile. The resulting patterns reveal that the South American Low-Level Jet as well as Mesoscale Convective Systems (MCS) play an enhanced role for the most extreme events.

[33] Acknowledgments. This paper was developed within the scope of the IRTG 1740/TRP 2011/50151-0, funded by the DFG/FAPESP, and the DFG research group FOR 1380 (HIMPAC). The authors thank Leila Carvalho and Charles Jones for stimulating discussions and comments.

[34] The Editor thanks two anonymous reviewers for their assistance in evaluating this paper.

\section{References}

Arraut, J. M., C. Nobre, H. M. J. Barbosa, G. Obregon, and J. Marengo (2012), Aerial rivers and lakes: Looking at large-scale moisture transport and its relation to Amazonia and to Subtropical Rainfall in South America, J. Climate, 25, 543-556, doi:10.1175/2011JCLI4189.1.

Berezin, Y., A. Gozolchiani, O. Guez, and S. Havlin (2012), Stability of climate networks with time, Scientific Reports, 2, doi:10.1038/srep00666.

Bookhagen, B., and M. R. Strecker (2008), Orographic barriers, highresolution TRMM rainfall, and relief variations along the eastern Andes, Geophys. Res. Lett., 35, L06403-1-L06403-6, doi:10.1029/ 2007GL032011.

Carvalho, L. M. V., C. Jones, and B. Liebmann (2002), Extreme precipitation events in southeastern South America and large-scale convective patterns in the South Atlantic convergence zone, J. Climate, 15(17), 23772394, doi:10.1175/1520-0442(2002)015<2377:EPEISS $>2.0$.CO;2.

Carvalho, L. M. V., C. Jones, and B. Liebmann (2004), The South Atlantic convergence zone: Intensity, form, persistence, and relationships with intraseasonal to interannual activity and extreme rainfall, J. Climate, 17, 88-108, doi:10.1175/1520-0442(2004)017<0088:TSACZI>2.0.CO;2.

Cohen, J., M. S. Dias, and C. Nobre (1995), Environmental conditions associated with Amazonian squall lines: A case study, Mon. Weather Rev., $123,3163-3174$.

Donges, J. F., Y. Zou, N. Marwan, and J. Kurths (2009a), Backbone of the climate network, EPL-Europhys. Lett., 87, 48007-p1-48007-p8, doi:10.1209/0295-5075/87/48007.

Donges, J. F., Y. Zou, and N. Marwan (2009b), Complex networks in climate dynamics, Eur. Phys. J. Special Topics, 174, 157-179, doi:10.1140/epjst/e2009-01098-2.
Donges, J. F., H. C. H. Schultz, N. Marwan, Y. Zou, and J. Kurths (2011) Investigating the topology of interacting networks, The European Physical Journal B-Condensed Matter and Complex Systems, 84, 635-651, doi:10.1140/epjb/e2011-10795-8.

Durkee, J. D., and T. L. Mote (2010), A climatology of warm-season mesoscale convective complexes in subtropical South America, Int. J. Climatol., 30, 418-431, doi:10.1002/joc.1893.

Durkee, J. D., T. L. Mote, and J. M. Shepherd (2009), The contribution of mesoscale convective complexes to rainfall across subtropical South America, J. Climate, 22, 4590-4605, doi:10.1175/2009JCLI2858.1.

Eltahir, E. a. B., and R. L. Bras (2006), Precipitation recycling in the Amazon basin, Q. J. Roy. Meteor. Soc., 120(051806), 861-880, doi:10.1002/qj.49712.

Garreaud, R., and J. Wallace (1997), The diurnal march of convective cloudiness over the Americas, Mon. Weather Rev., 12\$12), 3157-3171, doi:10.1175/1520-0493(1997)125<3157:TDMOCC >2.0.CO;2.

Gozolchiani, A., K. Yamasaki, O. Gazit, and S. Havlin (2008), Pattern of climate network blinking links follows El Niño events, $E P L$ Europhys. Lett., 83 (28), 28005-p1-28005-p5, doi:10.1209/0295-5075/ $83 / 28005$.

Gozolchiani, A., S. Havlin, and K. Yamasaki (2011), Emergence of El Niño as an autonomous component in the climate network, Phys. Rev. Lett., 107(148), 148501-1-148501-5, doi:10.1103/PhysRevLett.107. 148501 .

Grimm, A. M., and M. T. Zilli (2009), Interannual variability and seasonal evolution of summer monsoon rainfall in South America, J. Climate, 22, 2257-2275, doi:10.1175/2008JCLI2345.1.

Huffman, G., D. Bolvin, E. Nelkin, D. Wolff, R. Adler, G. Gu Y. Hong, K. Bowman, and E. Stocker (2007), The TRMM multisatellite precipitation analysis (TMPA): Quasi-global, multiyear, combinedsensor precipitation estimates at fine scales, J. Hydrometeor, 8, 38-55, doi:10.1175/JHM560.1.

Lettau, H., K. Lettau, and L. C. B. Molion (1979), Amazonia's hydrologic cycle and the role of atmospheric recycling in assessing deforestation effects, Mon. Weather Rev., 107(3), 227-238.

Malik, N., B. Bookhagen, N. Marwan, and J. Kurths (2011), Climate dynamics; Analysis of spatial and temporal extreme monsoonal rainfall over South Asia using complex networks, Clim. Dynam., 39, 1-17, doi:10.1007/s00382-011-1156-4.

Marengo, J. A., W. R. Soares, C. Saulo, and M. Nicolini (2004), Climatology of the low-level jet east of the Andes as derived from the NCEP-NCAR reanalyses: Characteristics and temporal variability, J. Climate, 17, 2261-2280, doi:10.1175/1520-0442(2004)017<2261: COTLJE $>2.0 . \mathrm{CO} ; 2$.

Marengo, J. A., et al. (2012), Recent developments on the South American monsoon system, Int. J. Climatol., 32, 1-21, doi:10.1002/joc.2254

Nicolini, M., A. C. Saulo, J. C. Torres, and P. Salio (2002), Enhanced precipitation over southeastern South America related to strong low-level jet events during austral warm season, Meteorologica, Special Issue for the South American Monsoon System, 27, 59-69.

Nogués-Paegle, J., K. C. Mo, and S. L. City (1997), Alternating wet and dry conditions over South America during summer, Mon. Weather Rev., 125(2), 279-291.

Nogués-Paegle, J., et al. (2002), Progress in Pan American CLIVAR research: Understanding the South American monsoon, Meteorologica, 27(12), 1-30.

Quiroga, R. Q., T. Kreuz, and P. Grassberger (2002), Event synchronization: A simple and fast method to measure synchronicity and time delay patterns, Phys. Rev. E, 66(4), 041904-1-041904-9, doi:10.1103/PhysRevE.66.041904.

Rheinwalt, A., N. Marwan, J. Kurths, P. Werner, and F.-W. Gerstengarbe (2012), Boundary effects in network measures of spatially embedded networks, EPL-Europhys. Lett., 100, 28002-p1-28002-p6, doi:10.1209/ 0295-5075/100/28002.

Salio, P., M. Nicolini, and A. C. Saulo (2002), Chaco low-level jet events characterization during the austral summer season, J. Geophys. Res., 107(D24), ACL 32-1-ACL 32-17, doi:10.1029/2001JD001315.

Salio, P., M. Nicolini, and E. J. Zipser (2007), Mesoscale convective systems over southeastern South America and their relationship with the South American low-level jet, Mon. Weather Rev., 135, 1290-1309, doi:10.1175/MWR3305.1.

Saulo, A. C., M. E. Seluchi, M. Nicolini, B. Aires, C. D. Previsa, and C. Paulista (2004), A case study of a Chaco low-level jet event, Mon. Weather Rev., 132(11), 2669-2683.

Steinhaeuser, K., A. R. Ganguly, and N. V. Chawla (2012), Multivariate and multiscale dependence in the global climate system revealed through complex networks, Clim. Dynam., 39(3-4), 1-7.

Tsonis, A., K. Swanson, and S. Kravtsov (2007), A new dynamical mechanism for major climate shifts, Geophys. Res. Lett., 34, 705-1-705-10, doi:10.1029/2007GL030288. 
BOERS ET AL.: SPATIAL PATTERNS OF EXTREME RAINFALL

Vera, C., et al. (2006), Toward a unified view of the American monsoon systems, J. Climate, 19, 4977-5000.

Yamasaki, K., A. Gozolchiani, and S. Havlin (2008), Climate networks around the globe are significantly affected by El Niño, Phys. Rev. Lett. 100(22), 228501-1-228505-4, doi:10.1103/PhysRevLett.100.228501.
Yamasaki, K., A. Gozolchiani, and S. Havlin (2009), Climate networks based on phase synchronization analysis track El-Niño, Prog. Theor Phys. Supp., 179, 178-188.

Zhou, J., K. M. Lau, J. O. F. Climate, and G. Space (1998), Does a monsoon climate exist over South America? J. Climate, 11(5), 1020-1040. 